\title{
Midazolam and Its Effect on Vital Signs and Behavior in Children Under Conscious Sedation in Dentistry
}

\author{
Jana VASAKOVA ${ }^{\mathbf{1}}$, Jana DUSKOVA ${ }^{\mathbf{1}}$, Jitka LUNACKOVA ${ }^{\mathbf{1}}$, Klara DRAPALOVA ${ }^{\mathbf{1}}$, \\ Lucie ZUZANKOVA ${ }^{1}$, Luboslav STARKA ${ }^{2}$, Michaela DUSKOVA ${ }^{2},{ }^{\dagger}$ Zdenek BROUKAL $^{1}$ \\ ${ }^{1}$ Institute of Dental Medicine, First Faculty of Medicine, Charles University and General University \\ Hospital, Prague, Czech Republic, ${ }^{2}$ Institute of Endocrinology, Prague, Czech Republic
}

Received February 12, 2020

Accepted March 11, 2020

\begin{abstract}
Summary
Midazolam is a short acting sedative with small number of adverse effects. Administered orally, it is currently the most common form of conscious sedation in children. The objective of this paper is to describe effect of midazolam administered to children during dental treatment on their vital signs, and to monitor changes in children's behavior. We described values of vital signs and behavior in 418 sedations conducted in 272 children between 1-12 years of age. To achieve the following results, we used data from 272 all first-time sedations. After administration of midazolam arterial blood pressure and blood oxygen saturation decreased by values which were not clinically significant. The heart rate increased, with values staying within the limits of physiological range. The speed of onset of midazolam's clinical effects depends on age and dose. The lower age and dose correlated with the higher behavior score. The effectiveness of midazolam treatment is $97.8 \%$. Unwillingness of child to receive midazolam is predictor for disruptive behavior during sedation. $1.8 \%$ of all sedation cases showed paradoxical reactions. The administration of midazolam in dose of $0.5 \mathrm{mg}$ per $1 \mathrm{~kg}$ of child's body weight is safe and could be recommended for dental treatment in pediatric dentistry.
\end{abstract}

\section{Key words}

Children • Conscious sedation • Vital signs • Dentistry • Midazolam

\section{Corresponding author}

J. Vasakova, Departement of Pediatric Dentistry, Institute of Dental Medicine, First Faculty of Medicine, Charles University and General University Hospital, Katerinska 32, 128 00, Prague 2, Czech Republic. E-mail: jana.vasakova@vfn.cz

\section{Introduction}

Midazolam is a substance belonging to the chemical family of imidazobenzodiazepines, synthetized by Fryer and Walser in 1976 (Walser et al. 1978). It is a colorless substance with a bitter taste, has poor solubility in water and becomes lipophilic at $\mathrm{pH}>4$. It is the imidazole ring that is responsible for the stability of midazolam in aqueous solutions and its rapid metabolism. This substance has a favorable ratio between wanted effects and adverse side effects. It has sedative, anterograde amnesic, central myorelaxant, hypnotic, anticonvulsant and anxiolytic effects (Kupietzky and Houpt 1993). These effects are caused by midazolam's nearly 2 times greater affinity to inhibitory GABA receptors than diazepam (Gerecke 1983). Among the adverse side effects of midazolam are diplopia, hiccups, loss of coordination and paradoxical reactions. Typical paradoxical reactions are agitation, excitation, and aggression towards people around them. When such a reaction occurs, administration of the antidote flumazenil is indicated (Davies et al. 1990). The exact mechanism behind the so called "angry child syndrome" remains unknown. Loss of a child's self-control due to the inhibitory effect of benzodiazepines is the most commonly considered cause. In some individuals, a similar reaction may be triggered by alcohol consumption. Another mechanism could be the reduction in serotonin transfer caused by benzodiazepines, where the subsequent reduction in serotonin triggers aggression (Mancuso et al. 2004). Midazolam was first used as a treatment of convulsions in children for its 
anticonvulsant properties (De Jong and Bonin 1984). Later, its sedative effects were used in indicated cases for premedication and sedation in pediatrics (Hronova et al. 2016). The method of treatment in which an adequate dose of a chemical substance is administered a certain time before an intervention and leads to sedation with maintained consciousness and protective reflexes is called conscious sedation (Craig and Wildsmith 2007). Depending on the administered drug, the patient must be prepared in terms of fasting and restricted liquid intake. It pharmacologically affects consciousness levels, hence perception, while protective reflexes remain preserved. It allows the airways to remain open so that patients can breathe independently, and thanks to preserved consciousness they can also react to physical and verbal stimuli. The duration of sedation depends on the respective sedative, route of administration and administered dose; this is associated with possible side effects.

Conscious sedation by midazolam has been used in dentistry since the late 1980s (Giovannitti 1987). The oral, intravenous, intranasal and rectal route of administration are possible for midazolam. One of the most commonly used sedatives in children in a dentist office is oral midazolam (Manso et al. 2019). Because of its bitter taste, for children we often mix it with a sweet syrup. Oral administration is preferred in pediatric dentistry because it does not cause anxiety during mild and moderate conscious sedation (Kupietzky and Houpt 1993, Manso et al. 2019). Other routes of administration used include intranasal or rectal application (Kupietzky and Houpt 1993).

Children are most commonly treated in sedation. The typical group includes preschool children, who still exhibit some of the primary fears (Rantavuori 2008) and whose levels of communication and coping abilities are low (Alwin et al. 1991). The character and extent of intervention indicate their treatment. Children perceive tooth extraction as worse than tooth filling (Milsom et al. 2003). Other often-performed procedures are surgical procedures such as a lingual frenectomy or the removal of supernumerary teeth, which are more time demanding. Without sedation, a child usually lacks the necessary patience. The other typical group of children treated in sedation includes "non-cooperating" children. These patients have usually undergone some intervention in the past which they subjectively perceived as traumatizing (Berge et al. 2002) and, as a result, do not cooperate during their next visits. Amnesia after sedation helps the child reestablish cooperation during following visits.

The scale of non-cooperation, i.e. the fear of a child, can be measured by various validated questionnaires. The questionnaire is either completed by an independent observer, mainly a parent, or subjectively as a self-evaluation by the child itself. In the latter case, we often opt for picture questionnaires such as the Venham picture test (Venham and Gaulin-Kremer 1979). Methods for assessing fear can be categorized into behavioral assessment, psychomotor methods, projective techniques, and physiological methods using the evaluation of indirect markers of anxiety (heart rate, skin basal reaction, muscle tension, etc.). The child's behavior is assessed using behavioral methods. The most frequently applied are clinical descriptions of behavior using the Frankl scale (Frankl et al. 1962) and Venham scale (Venham and Gaulin-Kremer 1979). The SEM scale is different (Wright et al. 1991): it assesses behavior as the sum of physiological parameters, i.e. sound expression (Sound), appearance of the eyes (Eye) and the child's motor reactions (Motor) (Table 1). The stress reaction can also be assessed based on saliva cortisol levels and saliva $\alpha$-amylase using laboratory methods (Duskova et al. 2017).

Table 1. Behavioral SEM scale.

\begin{tabular}{|c|c|c|c|c|}
\hline Parameter & Comfort & Mild discomfort & Moderate discomfort & Severe discomfort \\
\hline Grade & 1 & 2 & 3 & 4 \\
\hline Sound & no sound & $\begin{array}{l}\text { non-specific sound } \\
\text { (probable pain) }\end{array}$ & $\begin{array}{l}\text { verbal complaint, louder } \\
\text { sound }\end{array}$ & $\begin{array}{l}\text { verbal complaint } \\
\text { shouting, crying }\end{array}$ \\
\hline Eye & no sign & $\begin{array}{l}\text { dilated eye without tear } \\
\text { (anxiety sign) }\end{array}$ & $\begin{array}{l}\text { tears, sudden eye } \\
\text { movements }\end{array}$ & $\begin{array}{l}\text { crying, tears all over the } \\
\text { face }\end{array}$ \\
\hline Motor & $\begin{array}{l}\text { relaxed body and } \\
\text { hand status }\end{array}$ & $\begin{array}{l}\text { muscular contraction, } \\
\text { contraction of hands }\end{array}$ & $\begin{array}{l}\text { sudden body and hand } \\
\text { movements }\end{array}$ & $\begin{array}{l}\text { hand movements for } \\
\text { defense, turning the head } \\
\text { to the opposite side }\end{array}$ \\
\hline
\end{tabular}


The aim of this paper is to describe the effects of the administered sedative called midazolam on the levels of measured vital signs in children, and the occurrence and incidence of adverse effects. Also, the paper seeks to define the relationship between the intervention performed and the child's behavior. With this study, we would like to respond to inconsistent practice in the administration of midazolam to children in the Czech Republic and to our colleagues' concerns about possible complications during sedation.

\section{Material and Method}

\section{Study characteristics}

This retrospective study monitored the effects of perorally administered midazolam with syrup to children in order to induce conscious sedation between May 2018 and June 2019 at the Department of Pediatric Dentistry of the School of Medicine of $1^{\text {st }}$ Faculty of Medicine of Charles University and General University Hospital in Prague. All participants' parents signed an informed consent form on treating the child under conscious sedation, which included explanation of schedule of all examinations of vital signs and SEM score. We analyzed retrospectively these data, which were anonymized.

\section{Group characteristics}

During this 13 -month period, there were a total of 465 sedations performed in children from 1 to 12 years of age. The exclusion criteria for the study was any kind of illness (controlled asthma, allergy, autistic spectrum disorder, attention deficit hyperactivity disorder, etc.). The reason was to avoid any possible drug interactions or the effects of the administered midazolam on the child's behavior (Sekaninová et al. 2019). After the exclusion of children who did not meet the above mentioned criteria, of the 465 sedations we were left with 418 sedations performed on 272 children. For the average values and detailed characteristics of the whole group of 418 sedations $(139 / 51 \%$ boys and $133 / 49 \%$ girls, Table 2). Out of the 418 sedations performed, 161 children needed only 1 sedation to complete the planned treatment, 82 children needed 2 sedations, 23 children needed 3 sedations and 6 children needed 4 sedations. First-time sedation was performed in 272 children.

\section{Monitored values}

We monitored the following values: age of child at the time of sedation, gender, weight at the time of sedation (weighed at the Department of Pediatric Dentistry, the device used was an electronic bridge scale - the TSCALE FOX-II model RWP-3737-150M), administered dose of midazolam, willingness of the child to accept the medication, time of onset of the clinical effect, length of sedation, behavior during sedation (SEM scale, Table 1) (Wright et al. 1991), performed interventions, occurrence of paradoxical reaction, completion of the sedation, systolic blood pressure (SBP) and diastolic blood pressure (DBP) in 4 time intervals (before administering midazolam, right after the treatment performed under sedation, $30 \mathrm{~min}$ and $60 \mathrm{~min}$ after the treatment performed under sedation, measured by an MEC 1200 monitor, and all children by the same nurse), heart rate (HR) and oxygen saturation in the above mentioned 4 time intervals (measured by a pulse oximeter - Nonin Onyx Vantage 9590), presence of pain

Table 2. Characteristics of the whole group $(n=418)$.

\begin{tabular}{|c|c|c|}
\hline Whole group sedation & $\begin{array}{c}\text { Average } \\
\text { value }\end{array}$ & SD \\
\hline Age (years) & 5.5 & 1.84 \\
\hline Weight (kg) & 20.7 & 6.02 \\
\hline Dose (mg) & 9.2 & 1.72 \\
\hline Onset (min) & 28.8 & 7.02 \\
\hline Length of procedure (min) & 23.5 & 6.55 \\
\hline Behavior & 6.6 & 2.89 \\
\hline Number of fillings & 1.9 & 1.56 \\
\hline Number of extraction & 0.7 & 1.09 \\
\hline SBP before $(\mathrm{mm} \mathrm{Hg})$ & 109.0 & 10.17 \\
\hline DBP before $(\mathrm{mm} \mathrm{Hg})$ & 64.8 & 7.74 \\
\hline HR before & 98.2 & 14.08 \\
\hline $\mathrm{SpO}_{2}$ before & 98.8 & 0.93 \\
\hline SBP after (mm Hg) & 107.3 & 10.43 \\
\hline DBP after $(\mathrm{mm} \mathrm{Hg})$ & 63.3 & 8.57 \\
\hline HR after & 107.5 & 14.68 \\
\hline $\mathrm{SpO}_{2}$ after & 98.6 & 0.82 \\
\hline $\mathrm{SBP} 30 \mathrm{~min}(\mathrm{~mm} \mathrm{Hg})$ & 107.5 & 9.16 \\
\hline$D B P 30 \min (\mathrm{mm} \mathrm{Hg})$ & 64.1 & 7.08 \\
\hline$H R 30 \mathrm{~min}$ & 98.3 & 12.11 \\
\hline $\mathrm{SpO}_{2} 30 \mathrm{~min}$ & 98.5 & 1.07 \\
\hline SBP $60 \mathrm{~min}(\mathrm{~mm} \mathrm{Hg})$ & 107.4 & 7.80 \\
\hline $\mathrm{DBP} 60 \mathrm{~min}(\mathrm{~mm} \mathrm{Hg})$ & 62.9 & 6.59 \\
\hline$H R 60 \mathrm{~min}$ & 94.8 & 11.42 \\
\hline $\mathrm{SpO}_{2} 60 \mathrm{~min}$ & 98.7 & 0.71 \\
\hline
\end{tabular}

$\mathrm{SpO}_{2}$ - peripheral oxygen saturation, SBP - systolic blood pressure, DBP - diastolic blood pressure, HR - heart rate. 
after sedation (asking the child directly) and the $\mathrm{dmft} / \mathrm{DMFT}$ index of teeth. The decayed, missing and filled teeth index - dmft (for primary dentition)/DMFT (for permanent dentition), is the total number of teeth decayed, treated with fillings, or extracted in an individual due to carious destruction.

\section{Performing the sedations}

Sedations were performed according to the guidelines of the European Academy of Pediatric Dentistry (Guidelines on Conscious Sedation 2005) and the internal regulations of the General University Hospital (PP-VFN-065). All parents signed an informed consent form on treating the child under conscious sedation. The children did not eat or drink any unclear liquids $4 \mathrm{~h}$ prior to the procedure. Clear liquids could not be consumed later than $2 \mathrm{~h}$ before the procedure. During sedation, verbal contact was maintained and the child was also monitored visually by a dentist, who was performing the sedation. The administration of the medication $(0.5 \mathrm{mg} / 1 \mathrm{~kg}$ of the bodyweight up to maximum dose $12 \mathrm{mg}$ midazolam) was performed by a dentist with appropriate training in the recovery room, where the child was returned after the procedure was finished. The child stayed there for at least $2 \mathrm{~h}$ after the administration of the medication, monitored by a nurse and camera systems. In 9 children out of the 465 sedations, the procedure was not successfully completed as planned owing to disruptive behavior, and 5 children were administered flumazenil (Anexate) an antidote to midazolam - owing to the occurrence of a paradoxical reaction. It was possible to discharge all children into home care after $2 \mathrm{~h}$ post administration of medication; there were no conditions requiring extended monitoring. All the following results refer only to the group of first-time sedations, i.e. the 272 first-time sedations. The average age was 5.5 years $(\mathrm{SD}=1.95)$, weight $20.7 \mathrm{~kg}(\mathrm{SD}=6.02), 139$ boys $(51 \%)$ and 133 girls (49\%); the administered dose was $9.2 \mathrm{mg}(\mathrm{SD}=1.72)$. The average dmft value in boys was $7.15(\mathrm{SD}=3.88)$, 7.06 in girls $(\mathrm{SD}=3.72)$; there was no difference between the genders within this group. For more detailed characteristics of the group see Table 3. The aim of this study was to determine the effects of administered midazolam on the measured vital signs (arterial blood pressure, heart rate, and saturation) in children, specifically for the first-time sedation of a child, in order to rule out the effects of repeated sedation. We were also seeking to discover whether there is any significant relationship between the extent of decay, i.e. the $\mathrm{dmft} / \mathrm{DMFT}$ value, and the child's behavior during conscious sedation.

\section{Statistical evaluation}

With regard to the number of children, 4 groups were created according to individual procedures: one group with fillings, one group with extractions, another with prefabricated dental crowns and the final group with surgical intervention. For the quantitative data (age, weight, dose, SBP, DBP, HR, saturation, onset of action, duration of treatment, SEM score, number of fillings, and extractions), basic statistical characteristics were calculated, i.e. the average value and standard deviation. For the qualitative values (presence of pain and willingness to take midazolam), representation in each category was expressed in percent.

For the statistical analysis of continuous data (SBP, DBP, HR, saturation), we used the paired t-test, two-sample t-test, and the nonparametric Mann-Whitney test for subgroups with the number of monitorings less than 15, analysis of variance (ANOVA), and analysis of variance with repeated measuring and group factor. Also, Pearson correlation coefficients were calculated to assess the correlation between selected parameters (correlation between the onset of effect and weight, onset of effect and dose, dose and SEM score, age and SEM score, HR and SEM score, SBP and SEM score, and DBP and SEM score). The difference in the distribution of relative frequencies among the groups was assessed by chi-squared test in contingency tables, more precisely in the case of small frequencies by Fisher's exact test. All statistical tests were two-sided with a level of significance $\mathrm{p}<0.05$. Calculations were made using Microsoft Excel 2010 and the statistical software BMDP in version 8.1 (BMDP Statistical Software, Inc., Los Angeles, USA).

\section{Results}

Firstly, we analyzed a total of 465 sedations performed between May 2018 and June 2019. We followed the occurrence of paradoxical reactions in the observed group. There were five, which represent $1.1 \%$ out of the total of performed sedations. And then, we analyzed data of vital signs (saturation, systolic blood pressure, diastolic blood pressure, saturation and heart rate) during 418 sedations (Table 2). For detailed analysis, we selected only first-time sedations to do not have interference (experience with sedation, etc.). 
Table 3. Characteristics of the first-time sedation group $(n=272)$.

\begin{tabular}{|c|c|c|}
\hline First-time sedation & $\begin{array}{c}\text { Average } \\
\text { value }\end{array}$ & SD \\
\hline SBP before $(\mathrm{mm} \mathrm{Hg})$ & 109.7 & 10.11 \\
\hline DBP before ( $\mathrm{mm} \mathrm{Hg}$ ) & 65.2 & 8.20 \\
\hline HR before & 98.9 & 14.31 \\
\hline $\mathrm{SpO}_{2}$ before & 98.8 & 0.79 \\
\hline SBP after (mm Hg) & 108.1 & 10.68 \\
\hline DBP after $(\mathrm{mm} \mathrm{Hg})$ & 64.3 & 9.21 \\
\hline HR after & 107.2 & 14.81 \\
\hline $\mathrm{SpO}_{2}$ after & 98.6 & 0.83 \\
\hline $\mathrm{SBP} 30 \mathrm{~min}(\mathrm{~mm} \mathrm{Hg})$ & 108.4 & 9.59 \\
\hline DBP $30 \min (\mathrm{mm} \mathrm{Hg})$ & 64.2 & 7.39 \\
\hline$H R 30 \mathrm{~min}$ & 98.6 & 12.37 \\
\hline $\mathrm{SpO}_{2} 30 \mathrm{~min}$ & 98.4 & 1.07 \\
\hline SBP $60 \min (\mathrm{mm} \mathrm{Hg})$ & 107.4 & 8.01 \\
\hline DBP $60 \min (\mathrm{mm} \mathrm{Hg})$ & 63.4 & 6.82 \\
\hline$H R 60 \mathrm{~min}$ & 95.3 & 11.52 \\
\hline $\mathrm{SpO}_{2} 60 \mathrm{~min}$ & 6 & 0.76 \\
\hline
\end{tabular}

$\mathrm{SpO}_{2}$ - peripheral oxygen saturation, $\mathrm{SBP}$ - systolic blood pressure, DBP - diastolic blood pressure, HR - heart rate.

Table 4. Characteristics of vital signs according to gender.

\begin{tabular}{lcc}
\hline $\begin{array}{l}\text { First-time } \\
\text { sedation }\end{array}$ & Boys & Girls \\
\hline $\mathrm{SBP}$ before $/ \mathrm{SD}$ & $108.8 / 10.08$ & $110.8 / 10.06$ \\
$\mathrm{SBP}$ after $/ \mathrm{SD}$ & $107.8 / 10.87$ & $108.4 / 10.51$ \\
$\mathrm{SBP} 30 \mathrm{~min} / \mathrm{SD}$ & $106.9 / 10.24$ & $110.1 / 8.56$ \\
$\mathrm{SBP} 60 \mathrm{~min} / \mathrm{SD}$ & $106.5 / 7.81$ & $108.3 / 8.32$ \\
$\mathrm{DBP}$ before$/ \mathrm{SD}$ & $65.7 / 8.36$ & $64.6 / 8.05$ \\
$\mathrm{DBP}$ after $/ \mathrm{SD}$ & $63.7 / 8.40$ & $64.9 / 9.99$ \\
$\mathrm{DBP} 30 \mathrm{~min} / \mathrm{SD}$ & $63.8 / 7.89$ & $64.6 / 6.81$ \\
$\mathrm{DBP} 60 \mathrm{~min} / \mathrm{SD}$ & $63.4 / 7.29$ & $63.4 / 6.31$ \\
$\mathrm{HR}$ before $/ S D$ & $97.3 / 14.63$ & $100.5 / 13.92$ \\
$\mathrm{HR}$ after $/ \mathrm{SD}$ & $106.1 / 15.19$ & $108.5 / 14.48$ \\
$\mathrm{HR} 30 \mathrm{~min} / \mathrm{SD}$ & $98.8 / 12.16$ & $98.4 / 12.68$ \\
$\mathrm{HR} 60 \mathrm{~min} / \mathrm{SD}$ & $95.1 / 11.68$ & $95.1 / 11.29$ \\
$\mathrm{SpO} \mathrm{O}_{2}$ before $/ \mathrm{SD}$ & $98.9 / 0.77$ & $98.7 / 0.81$ \\
$\mathrm{SpO} \mathrm{O}_{2}$ after $/ \mathrm{SD}$ & $98.6 / 0.86$ & $98.6 / 0.82$ \\
$\mathrm{SpO} \mathrm{O}_{2} 30 \mathrm{~min} / \mathrm{SD}$ & $98.5 / 0.82$ & $98.4 / 1.28$ \\
$\mathrm{SpO} \mathrm{O}_{2} 60 \mathrm{~min} / \mathrm{SD}$ & $98.6 / 0.81$ & $98.6 / 0.69$ \\
\hline
\end{tabular}

$\mathrm{SpO}_{2}$ - peripheral oxygen saturation, $\mathrm{SBP}$ - systolic blood pressure, DBP - diastolic blood pressure, HR - heart rate.
Vital signs

The following was calculated for the values of vital signs in a group of 272 first-time sedations (Table 3). A significant decrease was demonstrated in systolic blood pressure (SBP, $\mathrm{p}=0.004)$, diastolic blood pressure $(\mathrm{DBP}, \mathrm{p}=0.03)$, saturation $(\mathrm{p}<0.001)$ and heart rate $(\mathrm{TF}, \mathrm{p}<0.001)$. We demonstrated a statistically significant decrease of $2.3 \mathrm{~mm} \mathrm{Hg}$ in SBP after the administration of midazolam compared to SBP measured $60 \mathrm{~min}$ after the treatment $(\mathrm{p}<0.001)$; there was no statistically significant difference between the other values. DBP had a statistically significant decrease by $1.8 \mathrm{~mm} \mathrm{Hg}$ in comparison with DBP measured $60 \mathrm{~min}$ after the treatment $(\mathrm{p}=0.002)$; there was no statistically significant difference between the other values. HR increased by 8.3 beats/min after administering midazolam compared to HR right after the treatment $(p<0.001)$. $30 \mathrm{~min}$ post treatment, HR remained the same as HR before the administration of midazolam, and HR-60 min post treatment decreased by 3.5 beats $/ \mathrm{min}$ in comparison with HR-30 min post treatment $(p<0.001)$. Saturation before administering midazolam was statistically significantly reduced by $0.35 \%$ in comparison with saturation measured $30 \mathrm{~min}$ post treatment $(\mathrm{p}<0.001)$; among the other values, there was a $0.2 \%$ difference in saturation values, which is a statistically significant difference.

\section{Differences in vital signs according to gender}

For changes in vital signs according to gender within the group of 272 first-time sedations, we demonstrated the following. To calculate the correlation of SBP, DBP, HR, saturation and gender, all 4 values were available in only 265 children (138 boys and 127 girls, Table 4). This was because not every child allowed us to measure blood pressure in all 4 required intervals. Children under 3 years did not cooperate very well. The partial values measured were physiological; children communicated and the saturation and heart rate stayed within the normal range. There was a difference between average values of SBP in all 4 measured intervals in boys and girls $(p=0.032)$; the trend shows a decrease in values over time for both genders; however, it is statistically insignificant. Average DBP and saturation did not differ between the genders at the measured intervals, and the trend showed values decreasing over time with no statistical significance. Average HR did not differ between the genders at the measured intervals, the trend was the same and 
statistically insignificant. The speed of onset of the sedation effect did not correlate with weight $(\mathrm{r}=0.105)$ but with age $(\mathrm{r}=0.14, \mathrm{p}<0.05)$ and dose $(\mathrm{r}=0.128, \mathrm{p}<0.05)$, with the dose determined by the weight of the child. The dose did not correlate with saturation, and correlated negatively with $\mathrm{HR}$ in all measured times $(\mathrm{r}=-0.295$, $\mathrm{r}=-0.309, \mathrm{r}=-0.381, \mathrm{r}=-0.371, \mathrm{p}<0.05)$; the greater the dose, the lower the HR. The dose positively correlated with SBP in all measured time intervals $(\mathrm{r}=0.3802$, $\mathrm{r}=0.1652, \mathrm{r}=0.2088, \mathrm{r}=0.2886, \mathrm{p}<0.05)$, i.e. the greater the dose, the greater the SBP. It correlated positively with DBP, but only before the sedation $(r=0.172, p<0.05)$ and did not correlate for the other times.

\section{Behavior}

To assess behavior, we used complete data from 271 children, of which 139 were boys and 132 girls. We did not find any statistically significant difference in behavior scores between boys (average $\mathrm{SEM}=6.5$, $\mathrm{SD}=2.83$ ) and girls (average $\mathrm{SEM}=6.8, \mathrm{SD}=2.94$ ). Nor did we find any correlation between the presence of pain after sedation and behavior score, between the $\mathrm{dmft} / \mathrm{DMFT}$ value and behavior score, the behavior score and saturation, or the behavior score and administered dose. On the contrary, we did demonstrate the following correlations: the younger the age, the higher is the SEM value $(\mathrm{r}=-0.272, \mathrm{p}<0.05)$, the lower the dose, the higher the SEM $(r=-0.227, \mathrm{p}<0.05)$, and the shorter the procedure, the higher the SEM $(\mathrm{r}=-0.211, \mathrm{p}<0.05)$. The SEM value in the measured intervals correlated with HR; the higher the behavior score, the higher the HR ( $\mathrm{r}=0.134$, $\mathrm{r}=0.398, \mathrm{r}=0.296, \mathrm{r}=0.205, \mathrm{p}<0.05)$. SEM also correlates with SBP, where the value of SBP grows with the value of SEM; however, only for SBP right after the treatment $(\mathrm{r}=0.211, \mathrm{p}<0.05)$. The same applied for DBP $(\mathrm{r}=0.149$, $\mathrm{p}<0.05)$.

We also studied the correlation between behavior and the performed procedure in selected groups, and the correlation between behavior and presence of pain after individual procedures (Table 5). There was a statistically significant difference in the presence of pain after treatment between children who had only had a filling and children who had only had tooth extraction $(\mathrm{p}=0.005)$, or only surgical intervention $(\mathrm{p}<0.001)$. Children who underwent an extraction or surgical intervention reported pain more often than the group who underwent a filling procedure. Then we compared the behavior of these 4 groups of children. Behavior during a surgical intervention was better than behavior during a filling procedure $(\mathrm{p}=0.008)$, during extraction $(p=0.018)$, and then behavior when treated with a prefabricated dental crown $(\mathrm{p}=0.006)$. There was no statistically significant difference between behavior during a filling procedure and extraction, a filling procedure and a prefabricated dental crown procedure, or extraction and a prefabricated dental crown procedure.

Table 5. Behavior related to the performed procedure (SEM scale).

\begin{tabular}{lcccc}
\hline $\begin{array}{l}\text { Performed } \\
\text { procedure }\end{array}$ & Number & $\begin{array}{c}\text { SEM } \\
\text { average } \\
\text { value }\end{array}$ & SD & $\begin{array}{c}\text { Pain } \\
\mathbf{n} / \mathbf{\%}\end{array}$ \\
\hline $\begin{array}{l}\text { Filling } \\
\text { Extraction }\end{array}$ & 110 & 6.7 & 2.85 & $1 / 0.9$ \\
$\begin{array}{l}\text { Prefabricated } \\
\text { dental crown }\end{array}$ & 13 & 6.8 & 3.06 & $5 / 12.8$ \\
$\begin{array}{l}\text { Surgery } \\
\text { intervention }\end{array}$ & 13 & 4.8 & 3.32 & $0 / 0$ \\
\hline
\end{tabular}

We also assessed the correlation between the willingness of the child to receive midazolam and their subsequent behavior. There were 272 children who were first-time sedated and received midazolam; however, only 271 were scored in SEM, therefore we calculated using 271 values. A majority of the children $(77.1 \%)$ drank the midazolam after explanation and without any need for persuasion, 47 children (17.4\%) needed explanation and persuasion, and 15 children $(5.5 \%)$ were administered midazolam using a syringe after their parents had granted consent. For this correlation, we demonstrated statistically significantly higher values of SEM within the second and third groups $(p=0.031$ and $p=0.023$, respectively).

\section{Discussion}

In terms of adverse effects within the observed group, there were 5 paradoxical reactions, i.e. in $1.8 \%$ of the children, which represents $1.1 \%$ out of the total of 465 performed sedations. Such a value corresponds with studies from abroad, which report a $1-2 \%$ rate of paradoxical reactions when performing sedations (Uldum et al. 2008, Massanari et al. 2016). The incidence of paradoxical reactions depends on age: it decreases with increasing age (Roelofse et al. 1990), which is in line 
with our findings, where 4 out of the 5 children were under 5 years old. We shall discuss the effects of administered midazolam on vital signs in children one by one. HR changes during the day, and therefore there is not a defined standard value, but rather a range given by interval between two values. This range is based on the age of the child, and in a preschool child heart rate may vary by $40-50$ beats per minute (Behrman et al. 2004). The demonstrated change in units, although statistically significant, has no clinical significance. This finding corresponds with the results of foreign studies, where after the administration of midazolam, HR ranges within the normal limits (Tavassoli-Hojjati et al. 2014). 4 children exceeded the upper limit of HR, which is $160 \mathrm{bpm}$. These were preschool children belonging to national minorities having a language barrier, and their behavior reached the upper limits of the SEM score. This mirrors the fact that, although such values can be reached physiologically during crying and protective movements, there is not any life-threatening situation.

Saturation remained above $95 \%$ during the entire course of sedation, which is a clinically accepted value of blood oxygen saturation (Behrman et al. 2004) and corresponds with the clinical observation of studies from abroad which were conducted the same way and with the same dose of midazolam (Lourenço-Matharu and Roberts 2010).

The statistically significant difference between SBP and DBP in boys and girls that we discovered corresponds with another study (Wang et al. 2012). The change of systolic blood pressure by $40-50 \mathrm{~mm} \mathrm{Hg}$ due to excitement, crying and physical activity is considered physiological in children (Behrman et al. 2004). Therefore, the changes in terms of units of $\mathrm{mm} \mathrm{Hg}$ that we measured, although statistically significant, have no clinical importance. Such changes in systolic pressure after the administration of midazolam correspond with results of studies from abroad (Wan et al. 2006). Diastolic blood pressure during the whole procedure corresponded with values based on age and height (O'Callaghan and Stephenson 2005). The standard deviation for diastolic blood pressure during the day is $9.5-9.7 \mathrm{~mm} \mathrm{Hg}$ (Wang et al. 2012). Although the decrease of DBP by $1.8 \mathrm{~mm} \mathrm{Hg}$ after administering midazolam is statistically significant, it has no clinical importance.

The greater the dose of administered midazolam, the higher the SBP and DBP, and the lower the HR. The administered dose corresponds with weight, which depends on the age and height of the child. Because the blood pressure increases with age (Behrman et al. 2004), we are getting increased values of BP. Saturation, which does not correlate with weight, age or height of the child, does not change with dose. The reduction in HR depends on the amount of administered midazolam, and although statistically significant, it has no clinical importance. The value of HR did not fall below the lower clinically determined limit in any of the children. The speed of onset of the clinical effects of administered midazolam correlates with age, which affects the pharmacokinetics of midazolam (Spina and Ensom 2007). The speed of onset also correlates with dose. The higher the administered dose, the longer the onset. The dose is calculated per $1 \mathrm{~kg}$ of the child's weight and, because the distribution volume increases with weight, the time of onset increases. The average time of onset that we recorded was $28.8 \mathrm{~min}$, and this is in line with studies that report $30 \mathrm{~min}$ for the same dose (Damle et al. 2008). Regarding the effectiveness of the administered dose, i.e. the number of completed procedures (which was $97.8 \%$ ), we are in keeping with the available studies (Manso et al. 2019).

The dmft/DMFT value is 7.15 in boys and 7.06 in girls and is nearly three times higher than reported in the last study conducted in the Czech Republic from the year 2012, where $\mathrm{dmft}=2.44$ (Lenčová and Broukal 2012). This high value correlates with the level of fear, since the level of fear grows with the amount of decay (Torriani et al. 2014). Such non-cooperating children are then referred for treatment with pharmacological support to a facility with a higher specialization. The insignificant difference between the dmft/DMFT of boys and girls corresponds with foreign studies (Vanobbergen et al. 2001). A detailed analysis of the high $\mathrm{dmft} / \mathrm{DMFT}$ value was not among the aims of our study, and with regard to a retrospective assessment it was not possible. Factors that increase the risk of caries activity can be divided into biological (more Streptococcus mutans in the mouth, the fluoride background of the child) and psychosocial (the child's attitude to oral hygiene, demographic data regarding care-givers, stress of the care-givers linked to expectations from their child, education, social class) (Quinonez et al. 2001). A closer analysis of, for example, taste preferences (Podzimek et al. 2018) in children treated under sedation would be interesting, as a preference for sweetness in early childhood results in children choosing sweet foods, therefore putting them at a higher risk of tooth decay. 
Treatment under sedation using midazolam has an impact on cooperation and therefore the behavior of children. We did not discover any difference between the behavior of boys and girls, which is supported by the conducted studies (Peretz et al. 2014). Nor does behavior correlate with the administered dose, because the dose depends on weight and the weight on the age of a child. With age, behavior improves as communication skills improve. The fact that the youngest children have the highest SEM scores, i.e. show the highest rate of non-cooperation, is linked to their poor coping abilities (Alwin et al. 1991). Our results, just as those from abroad (Gomes et al. 2019), show that child behavior during sedation improves with age. The discovery that interventions with the highest SEM scores are the shortest correlates with clinical practice, where due to disruptive behavior we often perform only the most acutely needed treatments. Although the effects of midazolam cannot be easily predicted due to the variability of receptors for benzodiazepines, our study revealed that unwillingness to receive midazolam is one of the possible predictors of disruptive behavior. The available literature does not discuss this fact. With a growing SEM value, values for SBP, DBP and HR also increase. This is a physiological phenomenon: the more disruptive the behavior, the more the child moves and the effect of sedation is less pronounced.

The presence of pain was more often reported by children who underwent extraction or surgical intervention. 2 groups of children are indicated for treatment under sedation: those who could not have their caries treated due to non-cooperation, and children who need to undergo a type of intervention for which they are not prepared in terms of developed coping abilities (e.g. surgical interventions) (Rantavuori 2008). The more they fear, the more they are sensitive to pain, as they lack the ability to cope with pain (Versloot et al. 2004). Best behavior is linked to surgical interventions other than extraction, which were performed in older children. This is associated with improved coping abilities and the natural reduction of primary fears with age (Chhabra et al. 2012).

At this time, when the topic of treating children in dental surgeries is being widely discussed, our study presents the second largest and, at the same time, the only study among the available literature that describes the values of arterial blood pressure, saturation and heart rate in a comprehensive way over several time intervals. In terms of the number of children, the largest study comes from 2010 and included 510 children (Lourenço-Matharu and Roberts 2010). This cited study describes data from 510 children treated over almost 30 months; we publish data from 272 children collected over the course of 13 months.

\section{Conclusion}

The administration of midazolam led to a statistically significant decrease in arterial blood pressure, which was an expected phenomenon; however, such decrease is absolutely insignificant from the clinical viewpoint. Heart rate stayed within the physiological range for the given age categories. The size of the group is sufficient for our data to confirm that the administration of midazolam is safe even for children in younger age categories, and such treatment may be recommended. The speed of onset of the clinical effects of midazolam depends on the age of the child. The amount of paradoxical reactions corresponds with current studies published in literature. We did not demonstrate any significant correlation between behavior and the $\mathrm{dmft} / \mathrm{DMFT}$ value. Unwillingness to receive midazolam is a predictor for non-cooperation during sedation. Older children demonstrate better behavior regardless of the performed procedure.

\section{Conflict of Interest}

There is no conflict of interest.

\section{Acknowledgements}

The study was created thanks to the support of PROGRES Q29/LF1.

\section{References}

ALWIN NP, MURRAY JJ, BRITTON PG: An assessment of dental anxiety in children. Br Dent J 171: 201-207, 1991. https://doi.org/10.1038/sj.bdj.4807661

BEHRMAN RE, KLIEGMAN R, JENSON HB: Nelson Textbook of Pediatrics. Saunders, Philadephia, 2004, pp 278, 1482-1483, 1487. 
CRAIG DC, WILDSMITH JA: Conscious sedation for dentistry: an update. Br Dent J 203: 629-631, 2007. https://doi.org/10.1038/bdj.2007.1105

CHHABRA N, CHHABRA A, WALIA G: Prevalence of dental anxiety and fear among five to ten year old children: a behaviour based cross sectional study. Minerva Stomatologica 61: 83-89, 2012.

DAMLE SG, GANDHI M, LAHERI V: Comparison of oral ketamine and oral midazolam as sedative agents in pediatric dentistry. J Indian Soc Pedod Prev Dent 26: 97-101, 2008. https://doi.org/10.4103/0970-4388.43186

DAVIES CA, SEALEY CM, LAWSON J, GRANT IS: Reversal of midazolam sedation with flumazenil following conservative dentistry. J Dent 18: 113-118, 1990. https://doi.org/10.1016/0300-5712(90)90098-y

DE JONG RH, BONIN JD: Benzodiazepines protect mice from local anesthetic convulsions and death. Anest Analg 60: 385-389, 1984. https://doi.org/10.1213/00000539-198106000-00003

DUSKOVA M, VASAKOVA J, DUSKOVA J, KAIFEROVA J, BROUKAL Z, STARKA L: The role of stress hormones in dental management behavioral problems. Physiol Res 66: 317-322, 2017. https://doi.org/10.33549/physiolres.933718

FRANKL S, SHIERE F, FOGELS H: Should the parent remain with the child in the dental operatory? J Dent Child 29: 150-163, 1962.

GERECKE M: Chemical structure and properties of midazolam compared with other diazepines. Br J Clin Pharmacol 16 (Suppl 1): 11S-16S, 1983.

GIOVANNITTI JA: Midazolam: review of a versatile agent for use in dentistry. Anest Prog 34: 164-170, 1987.

GOMES HS, DAHER A, COSTA PS, BATISTA AC, COSTA L: Crossover studies of pediatric dental sedation are inappropriate. Braz Dent J 30: 404-409, 2019. https://doi.org/10.1590/0103-6440201902852

HRONOVA K, POKORNÁ P, POSCH L, SLANAR L: Sufentanil and midazolam dosing and pharmacogenetic factors in pediatric analgosedation and withdrawal syndrome. Physiol Res 65 (Suppl 4): S463-S472, 2016. https://doi.org/10.33549/physiolres.933519

KUPIETZKY A, HOUPT MI: Midazolam: a review of its use for conscious sedation of children. Pediatr Dent 15: 237-41, 1993.

LENČOVÁ E, BROUKAL Z: Caries experience in Czech preschool children. (In Czech) Čes stomatol Prakt zubní lék 112: 168-172, 2012.

LOURENÇO-MATHARU L, ROBERTS GJ: Oral sedation for dental treatment in young children in a hospital setting. Br Dent J 209: E12-E12, 2010. https://doi.org/10.1038/sj.bdj.2010.886

MANCUSO CE, TANZI MG, GABAY M: Paradoxical reactions to benzodiazepines: Literature review and treatment options. Pharmacotherapy 24: 1177-1185, 2004. https://doi.org/10.1592/phco.24.13.1177.38089

MANSO MA, GUITTET C, VANDENHENDE F, GRANIER LA: Efficacy of oral midazolam for minimal and moderate sedation in pediatric patients: a systematic review. Pediatr Anesth 29: 1094-1106, 2019. https://doi.org/10.1111/pan.13747

MASSANARI M, NOVITSKY J, REINSTEIN LJ: Paradoxical reactions in children associated with midazolam use during endoscopy. Clin Pediatr 36: 681-684, 2016. https://doi.org/10.1177/000992289703601202

MILSOM KM, TICKLE M, HUMPHRIS GM, BLINKHORN AS: The relationship between anxiety and dental treatment experience in 5-year-old children. $\mathrm{Br}$ Dent J 194: 503-506, 2003. https://doi.org/10.1038/sj.bdj.4810070

O'CALLAGHAN C, STEPHENSON T: Pocket Paediatrics. Churchill Livingstone, Oxford, 2004, 415 p.

PERETZ B, KHAROUBA J, SOMRI M: A comparison of two different dosages of oral midazolam in the same pediatric dental patients. Pediatr Dent 36: 228-232, 2014.

PODZIMEK S, DUSKOVA M, BROUKAL Z, RACZ B, STARKA L, DUSKOVA J: The evolution of taste and perinatal programming of taste preferences. Physiol Res 67 (Suppl 3): S421-S429, 2018. https://doi.org/10.33549/physiolres.934026

QUINONEZ RB, KEELS MA, VANN WF JR, MCIVER FT, HELLER K, WHITT JK: Early childhood caries: analysis of psychosocial and biological factors in a high risk population. Caries Res 35: 376-383, 2001. https://doi.org/10.1159/000047477

RANTAVUORI K: Aspects and determinants of children's dental fear. Acta Universitatis Ouluensis, D Medica 991, University of Oulu, 2008. http://jultika.oulu.fi/files/isbn9789514289439.pdf 
ROELOFSE JA, STEGMANN DH, HARTSHORE J, JOUBERT JJ: Paradoxical reactions to rectal midazolam as premedication in children. Int J Oral Maxillofac Surg 19: 2-6, 1990.

SEKANINOVA N, MESTANIK M, MESTANIKOVA A, HAMRAKOVA A, TONHAJZEROVA I: Novel approach to evaluate central autonomic regulation in attention deficit/hyperactivity disorder (ADHD). Physiol Res 68: 531-545, 2019. https://doi.org/10.33549/physiolres.934160

SPINA SP, ENSOM MH: Clinical pharmacokinetic monitoring of midazolam in critically ill patients. Pharmacotherapy 27: 389-398, 2007. https://doi.org/10.1592/phco.27.3.389

TAVASSOLI-HOJJATI S, MEHRAM M, HAGHOO R, TOHID-RAHBARI M, AHMADI R: Comparison of oral and buccal midazolam for pediatric dental sedation: a randomized, cross-over, clinical trial for efficacy, acceptance and safety. Iran J Pediatr 24: 198-206, 2014.

TEN BERGE M, VEERKAMP JS, HOOGSTRATEN J: The etiology of childhood dental fear: the role of dental and conditioning experiences. J Anxiety Disord 16: 321-329, 2002. https://doi.org/10.1016/s0887-6185(02)00103-2

TORRIANI DD, FERRO RL, BONOW ML, SANTOS IS, MATIJASEVICH A, BARROS AJ, DEMARCO FF, PERES KG: Dental caries is associated with dental fear in childhood: Findings from a birth cohort study. Caries Res 48: 263-270, 2014. https://doi.org/10.1159/000356306

ULDUM B, HALLONSTEN AL, POULSEN S: Midazolam conscious sedation in a large Danish municipal dental service for children and adolescents. Int J Paediatr Dent 18: 256-261, 2008. https://doi.org/10.1111/j.1365263x.2007.00902.x

VANOBBERGEN J, MARTENS L, LESAFFRE E, BOGAERTS K, DECLERCK D: Assessing risk indicators for dental caries in the primary dentition. Community Dent Oral Epidemiol 29: 424-434, 2001. https://doi.org/10.1034/j.1600-0528.2001.290603.x

VENHAM LL, GAULIN-KREMER E: A self-report measure of situational anxiety for young children. Pediatr Dent 1: 91-96, 1979.

VERSLOOT J, VEERKAMP JS, HOOGSTRATEN J, MARTENS LC: Children's coping with pain during dental care. Community Dent Oral Epidemiol 32: 456-461, 2004. https://doi.org/10.1111/j.1600-0528.2004.00187.X

WALSER A, BENJAMIN LE SR, FLYNN T, MASON C, SCHWARTZ R, FRYER RI: Quinazolines and 1,4-benzodiazepines. 84. Synthesis and reactions of imidazo (1,5 -a) (1,4)-benzodiazepines. J Org Chem 43: 936-944, 1978. https://doi.org/10.1021/jo00399a029

WANG Z, MA J, DONG B, SONG Y, HU PJ, ZHANG B: Comparison of blood pressure levels among four age groups of Chinese children matched by height. J Hum Hypertens 26: 437-442, 2012. https://doi.org/10.1038/jhh.2011.45

WAN K, JING Q, ZHAO JZ: Evaluation of oral midazolam as conscious sedation for pediatric patients in oral restoration. Chin Med Sci J 21: 163-166, 2006.

WRIGHT GZ, WEINBERGER SJ, MARTI R, PLOTZKE O: The effectiveness of infiltration anesthesia in the mandibular primary molar region. Pediatr Dent 13: 278-283, 1991. 